\title{
Leitura comparada de textos africanos escritos por mulheres
}

\author{
Ana Maria Mão-de-Ferro Martinho \\ Universidade Nova de Lisboa
}

\begin{abstract}
RESUMO: REALIZA-SE UMA REFLEXÃO SOBRE A ESCRITA DE AUTORIA FEMININA, A SUA ABRANGÊNCIA E SUAS LIMITAÇÕES, EXAMINANDO-SE MAIS DETIDAMENTE TEXTOS DE AUTORAS DE ANGOLA, CABO VERDE E MOÇAMBIQUE.
\end{abstract}

ABSTRACT: A REFLECTION ON THE FEMININE WRITING AUTHORSHIP, ITS RANGE, ITS LIMITATIONS IS CARRIED OUT, BY EXAMINING MORE EMPHATICALLY TEXTS OF AUTHORS FROM ANGOLA, CAPE VERDE AND MOZAMBIQUE.

PALAVRAS-CHAVE: LITERATURA DE AUTORIA FEMININA, FEMINISMO AFRICANO; PAULINA CHIZIANE, ORLANDA AMARÍLIS, DINA SALÚSTIO, PAULA TAVARES.

KEY-WORDS: FEMININE AUTHORSHIP LITERATURE, AFRICAN FEMINISM, PAULINA CHIZIANE, ORLANDA AMARÍLIS, DINA SALÚSTIO, PAULA TAVARES. 


\section{Limites hermenêuticos}

nosso estudo sobre literatura escrita por mulheres em países como Angola, Cabo Verde e Moçambique, tem-se baseado muito freqüentemente na procura da validação de duas vertentes: a da existência de um quadro estético e ético comum que autorize a sua associação e leitura comparada; a da pesquisa simultânea de traços distintivos que permitam levar essa afinidade para terrenos de interrogação dos seus limites hermenêuticos.

Ao pensarmos numa resposta ao tema do encontro sobre "Lusofonia e Viagem" pareceu-nos de toda a oportunidade avaliar estas hipóteses à luz de uma reflexão sobre a viagem, lida do lado da mobilidade (sob as múltiplas formas de uma cultura de exílio ou diáspora) e da permanência, em que o valor simbólico dos caminhos se faz para acentuar o exercício de saberes ancestrais e não o da experiência da multiplicidade dos espaços físicos.

Uma pergunta que desde logo nos ocorre e que pode levar à revisão de muito do que se tem dito e escrito, por nós, nomeadamente, é a de sabermos até que ponto este problema é em primeiro lugar uma questão de género ou histórico-cultural. Sendo um problema de género, significa necessariamente que estas escritoras contribuem para a construção de um discurso que as implica como fazendo parte de um grupo que procura, com consciência absoluta ou não desse facto, as bases de uma cultura e de uma ideologia de reivindicação e conquista de espaço simbólico. O seu envolvimento na leitura dos valores de dimensão tradicional (ainda um critério validado por muitos dos intelectuais africanos, embora claramente discutível na sua vertente mais essencialista), deixa-as na situação ambígua e incómoda de reconhecerem a necessidade de um compromisso com o passado colectivo e a evidência de anacronismos socioculturais que as afectam directamente.

Ou seja, por um lado é fácil identificarmos na escrita destas autoras a revisão de culturas de extracção ancestral e o uso de muitos dos seus significados como medida de integração histórica perceptível, e simultaneamente a construção sobre esse substracto de um discurso ideológico de dimensão transcontinental.

Recentemente, ao lermos um texto em que se discutia a relação das mulheres sul-africanas com a opressão racial e com a opressão sobre as mulheres (Wilkinson, 2003, p. 343-360), apercebemo-nos deste caso como um dos exemplos no limite dessa problemática. Em 1991 teve lugar em Durban uma conferência 
sobre "Women and Gender" e logo no ano seguinte uma outra, na Nigéria, intitulada "African Women's Diaspora in Nigeria", que foram decisivas para colocar diversos problemas, embora suscitando na altura mais conflitos do que respostas. Esses conflitos nasceram então da dificuldade de entendimento entre académicos e activistas, mulheres brancas e negras, mulheres africanas e afro-americanas. Entre acusações mútuas de legitimidade patrimonial da origem e identidade africanas, as sul-africanas brancas acabaram por se ver no meio de uma discussão em que as africanas negras até então exiladas na Europa vieram em sua defesa, reconhecendo-lhes o direito de participação activa na leitura de mundos africanos, em especial naqueles protagonizados por mulheres negras.

Trata-se em boa verdade de reconhecer ou não que as mulheres de origem africana são responsáveis por respostas, em contexto pós-colonial ou pósapartheid, com contornos privados, baseados na sua experiência de África, sendo que a legitimidade desses discursos se circunscreve ao modo de ler e escrever sobre os sujeitos e objectos dos diferentes fenómenos de opressão.

Muito embora estes problemas ainda suscitem diversas formas de incomodidade, uma vez que a herança dos constrangimentos raciais, de género e de classe, não está necessariamente resolvida, deve dizer-se que a Constituição sul-africana é hoje uma das mais progressistas no respeitante ao lugar das mulheres na sociedade e nos órgãos de decisão (2003, p. 345) e, como tal, tem-lhes sido reconhecido direito a um estatuto muito tempo negado.

Invocamos este exemplo, em boa medida distante das realidades que nos ocupam directamente neste texto, porque ele pode ajudar-nos a compreender que os fenómenos de pertença a um determinado espaço têm uma natureza contingente, baseada na História colectiva e nas diferentes histórias individuais, mas também simbólica e representacional, pela leitura de múltiplas formas de alteridade.

É nesse sentido, nomeadamente, que podemos reconstituir as diversas formas de localização e deslocalização cultural.

\section{Feminismo Africano ou Dupla Colonização?}

Muitos têm considerado o feminismo africano como necessário ao acompanhamento de todos os fenómenos de variação social. Tanto uma estética 
feminista como um discurso pós-colonial retêm a afinidade de uma mudança de paradigmas em face de sociedades em busca de modelos reformistas de desenvolvimento. No entanto, em boa parte desta mudança parece existir uma gestão muito diversa de prioridades: para as mulheres escritoras, nomeadamente, falar de sociedade pós-colonial é frequentemente denunciar ao mesmo tempo as injustiças de sistemas patriarcais. A impossibilidade reconstrutiva de um modelo favorável aos valores africanos, que se justificaria como oposição ao discurso colonial, é com freqüência o traço dominante na escrita literária de mulheres (Petersen, 2003, p. 251-254).

A noção de "dupla colonização", adoptada por muitos autores, justifica precisamente o que acima referimos: as mulheres africanas foram, e são, duplamente colonizadas: primeiro pelas ideologias imperialistas, depois pelas patriarcais.

Esta situação suscita uma outra: quem tem legitimidade para falar sobre estas realidades? Quem pode fazer a respectiva denúncia e ver os seus textos aceites nas comunidades de referência?

No fundo era isso que se discutia na África do Sul e na Nigéria nos anos 90: tem essa legitimação que ser claramente empírica e baseada nas experiências individuais? Pode ser justificada por critérios de natureza racial ou de género, sejam quais forem as circunstâncias culturais que lhes estão na origem? O essencialismo da segunda hipótese convence muito poucos hoje em dia, o que não lhe retira importância como hipótese de leitura crítica em diversas obras e textos.

Os dois exemplos que a seguir apresentamos são significativos da dificuldade de consideração deste problema.

Na sua obra Niketche, Paulina Chiziane guia-nos através da realidade social complexa de Moçambique, dos conflitos entre homens e mulheres no espaço da organização da família e da construção do estatuto social da mulher. A permanência de valores da sociedade patriarcal, nomeadamente perceptíveis na poligamia informal, gera uma guerra pela substituição de papéis, em que as mulheres assumem uma estratégia colectiva de redução do poder do homem. A alegoria é clara: enquanto grupo, as mulheres são o poder. Nasce desta forma a rejeição da "duplicidade colonial" no sentido em que as diferentes formas de opressão se tornam modelos de contingência absoluta.

Por outro lado, ao retratar a cultura através de uma visão marcada por estereótipos, na sua curiosa e simplificada leitura das diferenças entre o Sul e o 
Norte, Chiziane propõe o modelo de uma etnicidade essencialista do homem e da mulher de Moçambique.

Ao aceitá-lo, constrói um discurso que é, antes de tudo, ideológico e programático.

Das transições entre o Norte e o Sul emerge uma iconografia que só não é panfletária nos momentos de assumido intimismo.

O sentido da viagem nesta autora vem associado a duas formas de experiência: a da personagem central, que faz todo um percurso movido para a construção de conhecimento, fazendo depender dessa experiência um fenómeno de generalização em que as restantes personagens são funcionalmente definidas por ela; a dos leitores, sendo que se trata de uma relação de cumplicidade permanente. Espera-se de nós que saibamos compreender a situação das mulheres envolvidas na narrativa. Este é um diálogo de classe entre mulheres instruídas; a viagem proposta é a de construção de um "topos" cultural onde esse encontro se concretize na afinidade de um universo ideológico cúmplice.

A alegoria do rio que corre ilustra claramente este percurso em direcção a um outro lugar. Este é um lugar no entanto que revê imagens convencionais. Trata-se de um rio inamovível, sem fluxo que acompanhe ou marque o fluir do tempo.

"A minha vida é um rio morto. No meu rio as águas pararam no tempo e aguardam que o destino traga a força do vento. No meu rio, os antepassados não dançam batuques nas noites de lua. (...) Meu Deus, ajuda-me a descobrir a alma e a força do meu rio". (2002, p. 35)

Esta é uma viagem que remete para a permanência, mas para uma permanência indesejada, em conflito com os valores ancestrais (veja-se a imagem iconográfica do batuque). A vontade de superação deste estigma aparece vertida na dimensão confessional, contraditória em relação ao voluntarismo de outros momentos.

Este percurso é por isso, e antes de mais, cultural: qual é o lugar da minha cultura? Possivelmente não o da proximidade activa dos mundos africanos, mas algum outro no limiar de experiências generalizáveis.

Em Dina Salústio, caboverdiana, autora de A louca de Serrano (2001), esperaríamos diferenças significativas em relação a estes pressupostos. Curiosamente, 
também no caso desta autora, proveniente embora de uma sociedade profundamente diversa, podemos identificar fenómenos semelhantes.

Donde uma conclusão se pode retirar: as questões que se colocam à dimensão africana destes textos não são relacionáveis com problemas de raça, mas de género e de classe.

Neste segundo caso, algumas metáforas são levadas mais longe, sendo também mais radical a forma de olhar para o homem e para a mulher, no sentido em que as suas diferenças são discutidas na base da fertilidade demonstrada. Uma vez mais, interroga-se a ordem social do lugar do homem, da maternidade exigível à mulher como justificação da sua existência social.

A ausência de fertilidade nos homens explica o papel autoritário das mulheres e da sua gestão de segredos que a eles são vedados. Assim, deixa de haver lugar para os homens como líderes de existências colectivas, para passar a haver uma clara revisão do seu papel através da acção das mulheres. Não se trata de os substituir no seu lugar mas de os controlar por via da anulação das suas mais periféricas e estereotípicas qualidades.

O que se nos afigura de valor simbólico incontornável, ainda neste romance, é a dimensão da loucura, associável a todas as formas de exclusão. Não nos parece razoável falar de dupla colonizaçao neste caso, antes se trata de uma forma de desconstrução do lugar do homem, sendo que essa desconstrução se gera a partir de mistérios só acessíveis às mulheres.

A viagem tem neste caso a dimensão da própria insularidade que é sobretudo defensiva. Trata-se de um mundo controlado por mulheres porque só elas conhecem a origem comum da sua maternidade. Todos os percursos servem para a sustentação de insularidades privadas, asseguradas por linguagens igualmente exclusivas.

\section{Fronteiras e Sinais}

Curiosamente, a tão proclamada insularidade como fenómeno de permanente deriva e motivação para a viagem em direcção ao exterior e para a transição entre espaços marcantes na cultura caboverdiana, não aparece nem em Salústio nem em Orlanda Amarilis, também caboverdiana. 
Todas as narrativas desta autora se constroem de acordo com uma lógica de preservação dos espaços interiores e esses espaços são inteiramente habitados por mulheres. Enquanto para a primeira escritora se pode falar de instauração de um discurso feminista, na segunda não se perverte a ordem patriarcal, ela mantém-se intacta, mas são acentuados os fenómenos de construção de sinais só a elas acessíveis.

Neste caso, a viagem é apenas a procura da alteridade através da dimensão dos universos interiores.

A obra Cais do Sodré té Salamansa (1991) inscreve no próprio título a viagem representativa de uma vivência de diáspora. Ora esta viagem só é perceptível através da própria experiência e das mulheres que realizam os diferentes percursos. Através da memória, nomeadamente. Não é necessariamente uma viagem física, como os títulos das narrativas podem sugerir, mas percursos com dimensões de percepção para lá do real empírico. São viagens que se baseiam num tempo desconstruído.

A dimensão dos sinais a descodificar aparece acentuada na forma como Paula Tavares, autora angolana, em Dizes-me coisas amargas como os frutos (2001), constrói as virtudes de um lugar marcado por sinais só acessíveis a iniciados nas culturas de referência. Não ocorre neste caso nenhuma tensão entre homem e mulher, são ambos determinados por valores maiores da experiência colectiva.

Trata-se de organizar formas de pertença a uma cultura de imersão. Em todo o caso, o acesso a esse conhecimento faz-se de fora para dentro e não é garantido que se consiga resposta a todos os mistérios iniciados. A reconstrução de metáforas e o exercício associativo e analógico de ideias instaura um espaço de discurso aberto à experiência e à leitura mitológica dos caminhos possíveis. Não estamos a considerar uma leitura vertical das relações humanas, tão pouco do próprio conhecimento. Falamos, isso sim, de uma experiência de dimensão horizontal que organiza os códigos da leitura mitológica e não desconstrutiva do mundo. Será, pode dizer-se, uma dupla leitura.

A imagem do estrangeiro aparece no poema a seguir parcialmente citado como a de alguém que instaura instabilidade e receio, assinalando as mudanças que ocorrem de fora para dentro, podendo gerar cortes na existência cognoscível, da comunidade. 
“estrangeiro/ontem não nasceu ninguém no ehumbo/e a lua estava alta e nova/o velho que sofre/ não conseguiu morrer (...)"

Esta poesia interroga a autoridade das sínteses culturais e resiste à homogeneidade cultural no mesmo sentido em que apresenta símbolos e ícones revisitados. O arcaísmo aqui não surge como artifício construído em nome de autoridades representadas mas é valor de uma original textualidade iterativa.

\section{Outro no Lugar que Sou Eu}

Em Maria Alexandre Dáskalos, também angolana, importa considerar o lugar da diáspora. A diáspora está na origem da forma mais disjuntiva de exercício da distância e da identidade. A dualidade cultural que implica esta forma de projecção em relação aos espaços de referência traz consigo o peso de enigmática instabilidade e reavaliação constante do lugar de si e do lugar em que se está. Pela sua natureza transitória é também o espaço de um "relativismo da distância"(Ashcroft, 2003, p. 207), em definição de Williams, de uma negação tanto da leitura unitária da cultura como do dualismo da relação de si com o Outro.

Ao viver em permanência como um Outro, abre-se ao sujeito da experiência textual a possibilidade de exercício crítico marcado pela reinterpretação politica da cultura.

"Acho que não chegámos a falar de/ rinocerontes./Naquele tempo eram só palavras,/só podia haver palavras./Mas, agora, ouvi dizer/que as lágrimas dos rinocerontes/são o ouro da alquimia." (Dáskalos, 2001).

Esta diversidade contribui para a construção de uma luta libertadora, criando efeitos de descontinuidade criativa possíveis através das formas como os sistemas culturais operam para sugerir diferentes modos de representação linguística e performativa das culturas.

Estamos perante um universo de efeitos semióticos naturalmente disjuntivos, que podem criar efeitos contraditórios e imprevisíveis entre os enunciados antecipados e os sujeitos de enunciação. Desta disjunção emergem formas diversas de ler e de prever a produção de discursos, sendo que, como diz Homi Bhabha, "meaning is never simply mimetic and transparent" (Ashcroft, 2003, p. 207). 
* Publicado em "Lusofonia e Viagem" - Universidade da Extremadura - Cáceres - 2006

\section{Referências bibliográficas:}

AMARILIS, Orlanda. Cais-do-Sodré té Salamansa. Linda-a-Velha: Alac, 1991.

ASHCROFT, B. at all. (Ed). The Post-Colonial Studies Reader. Londres: Routledge, 2003.

CHIZIANE, Paulina. Niketche, Lisboa: Caminho, 2002.

DÁSKALOS, Maria Alexandre. Lágrimas e laranjas. Lisboa: Caminho, 2001.

PETERSEN, K.H.Petersen. First Things First - Problems of a Feminist Approach to African Literature. In ASHCROFT, B. et all (Ed). The Post-Colonial Studies Reader. Londres: Routledge, 2003, p. 251-254.

SALÚSTIO, Dina. A louca de Serrano. $2^{\text {a }}$ ed. São Vicente: Spleen, 2001.

TAVARES, Paula. Dizes-me coisas amargas como os frutos. Lisboa: Caminho, 2001.

WILKINSON, Jennifer. South African women and the ties that bind. In The African

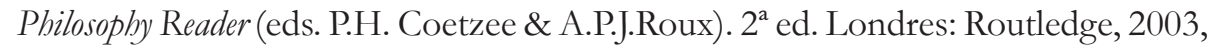
p. 343-360. 